\title{
DEL SENTIDO RELIGIOSO DE LA VIDA EN TOLSTÓI, A LA MELANCOLÍA DE CHÉJOV
}

\section{FROM TOLSTOY'S RELIGIOUS MEANING OF LIFE TO CHEKHOV'S MELANCHOLIA}

\author{
Nicolás Sánchez Durá ${ }^{1}$ \\ Universidad de Valencia (España)
}

Recibido: 30-11-2014

Aceptado: 02-02-2015

Resumen: Se compara Una historia aburrida de Antón Chéjov con La muerte de Iván Ilich de León Tolstói con el fin de dilucidar distintos modos de la crisis de sentido que se fragua a finales del siglo XIX y principios del siglo XX. El relato de Tolstói prefigura la reconstrucción de un sentido de índole religiosa (una humanidad regida por los principios de fraternidad y de no resistencia violenta frente al mal, considerada como el reino de Dios entre nosotros), mientras que Chéjov aceptaría el dictum de Wittgenstein «Creer en un dios significa ver que la vida tiene un sentido» pero no cree que haya dios alguno en que creer. Por último, se pregunta qué moral puede derivarse de tal negación y se recurre para responder a Vida y Destino de V. Grossman.

Palabras-clave: sentido de la vida, sinsentido, L. Tolstói, A. Chéjov, V. Grossman.

\begin{abstract}
Anton Chekhov`s A Boring Story is compared with Leon Tolstoy's The Death of Ivan Ilyich in order to elucidate the forms of meaning crisis that appear in the late nineteenth century. While Tolstoy's story foreshadows the reconstruction of a kind of religious meaning (humanity governed by the principles of brotherhood and non-violent resistance to evil regarded as the kingdom of God among us), Chekhov would accept Wittgenstein's dictum "To believe in a God means to see that life has a meaning", even though he does not think there is any god to believe in. Finally, which morality can result from such denial is discussed and V. Grossman's Life and Fate is used to answer Key-words: meaning of life, nonsense, L. Tolstoy, A. Chekhov, V. Grossman.

[1] (Nicolas.Sanchez@uv.es) Director del Dpto. de Metafísica y Teoría del Conocimiento de la Univ. de Valencia. Sus líneas de investigación son la antropología filosófica y la filosofía contemporánea. En torno al asunto que aquí se trata ha publicado recientemente "Muerte y religión: del Tolstói maduro al joven Wittgenstein" en Logos 45, 2012; "Wittgenstein on war and peace" en Perissimotto, L. (edit.): The darkness of this time: ethics, politics, and religion in Wittgenstein. Milán: Mímesis,
\end{abstract} 2014. Cf. así mismo nota al pie $\mathrm{n}^{0} 4$. 
En la nota 2 a pie de página del parágrafo 51 de Ser y Tiempo, de título «El estar vuelto hacia la muerte y la cotidianidad del Dasein», Heidegger afirma: "En su relato La muerte de Iván Ilich L.N. Tolstói ha presentado el fenómeno de la conmoción y el derrumbe de este "uno se muere'». ${ }^{2}$ Por este «uno»-que se conmociona y derrumba- Heidegger entiende el hombre medio, inmerso en la inmediatez de su cotidianidad, que vive siempre en el sobrentendido de que no es él quien morirá sino el Sócrates del silogismo -ya saben: «todos los hombres son mortales, Sócrates es hombre, luego...». Pues bien, mi intención aquí es mínima: considerar a Antón Chéjov en la dilucidación de la crisis de sentido que se fragua en el último tercio del siglo XIX. Crisis del sentido que tuvo manifiesta significación en mucha de la reflexión filosófica de la primera mitad del siglo XX, pero cuya dimensión, por sus implicaciones morales y políticas, todavía perdura.

Por tanto no voy a tematizar la interculturalidad, asunto de este congreso, sino que voy a ejercerla, o eso espero. Pues voy a reflexionar junto a dos, ya veremos que al cabo son tres, de los más grandes escritores rusos. Para ello comentaré dos relatos breves y al final implicaré, se verá por qué, Vida y Destino, la gran obra del escritor judeo-ruso Vasili Grossman. En lo que respecta a Chéjov voy a centrarme en una de sus nouvelles, Una historia aburrida (en ocasiones el título se traduce como Una historia banal), en la que entra en claro diálogo con el Tolstói posterior a Confesión y, en particular, con su breve relato La muerte de Iván Ilich. Este es un estímulo que nos viene de Rusia, de una Rusia lejana en el tiempo y creo, como recomendara Paul Ricoeur en un breve texto, "Le dialogue des cultures», ${ }^{3}$ que debiéramos recuperar los caminos que quedaron cortados, volverlos a andar y así hacer posible retejer con más hebras, que quedaron como cabos sueltos, nuestra intrincada malla cultural.

Una Historia aburrida se publicó en 1889 con el título Mi nombre y yo sólo tres años después de la aparición de La muerte de Iván Ilich. Al igual que el relato de Tolstói su nervio central es la ausencia de sentido de la vida revelada con ocasión no de una experiencia límite-como es la enfermedad terminal en el caso de Iván Ilich-, sino a través de la experiencia de la decrepitud propia del envejecer. Pero a diferencia del caso de Tolstói, la herida de esa ausencia, aunque estimada en apariencia de forma ambivalente, es más radical en su alcance. Mientras que el relato de Tolstói prefigura la reconstrucción de un sentido de índole religiosa inscrito en un cristianismo peculiar (una humanidad regida por los principios de fraternidad y de no resistencia violenta frente al mal, considerada como el reino de Dios entre nosotros, filosofía que Tolstói

[2] Heidegger, M.: Ser y Tiempo. Traducción, prólogo y notas de Jorge Eduardo Rivera. Madrid: Trotta, 2000, p. 274.

[3] Véase Ricoeur, P.: «Le dialogue des cultures» en VV.AA: Aux sources de la culture Française. Paris: Éditions la Découverte, 1997.

THÉMATA. Revista de Filosofía, ${ }^{\circ} 52$ julio-diciembre (2015) pp.: 111-127 doi: 10.12795/themata.2015.i52.06 
desarrollará en su obra posterior), ${ }^{4}$ en el relato de Chéjov no hay esperanza posible. Chéjov aceptaría el dictum de Wittgenstein "Creer en un dios significa ver que la vida tiene un sentido», ${ }^{5}$ pero a diferencia de éste no cree que haya dios alguno, siquiera sea con minúscula, en que creer. Tolstói escribió en tercera persona La muerte de Ivan Ilich en torno a los 50 años de edad. Un narrador omnisciente es quien da la voz de forma intermitente al personaje central y siempre en estilo indirecto; cuando Iván Ilich muere, el relato de Tolstói acaba. Una historia aburrida tiene la forma de las memorias de un hombre de 62 años, Nicolás Stepanovitch, escritas por un Chéjov que tan solo contaba 29 años y poco después de que su hermano Nicolai muriera a pesar de los amorosos cuidados que le dedicó. Todo el relato es la narración en primera persona de un ser angustiado por una indiferencia melancólica de la que solo se salva la intención de vivir de forma valiente e irreprochable su tiempo final. Cuando esa indiferencia se instala irrevocablemente decide permanecer en silencio y el relato acaba. El punto de vista de Chéjov es complejo y en ocasiones de apariencia contradictoria o paradójica. Mi intención es mostrar esa complejidad como un momento clave de las filosofías existenciales del siglo XX, también pensar qué moral pudiera ser acorde con su punto de vista vital.

Nicolás Stepanovich, célebre profesor de medicina en la universidad, aparece escindido desde el arranque del relato. Por una parte su nombre, mejor: su renombre, es decir, su estatus social y jerarquía académica, su prestigio profesional reconocido en Rusia e internacionalmente. Por otra, la percepción de sí mismo y, en primer lugar, de su cuerpo decrépito de un hombre de 62 años. Una decrepitud que no sólo se muestra en las marcas corporales, los dientes postizos, el rostro raido, neuralgia incurable, etc. A todo ello se añade, o de ello se deriva, la decadencia de su agudeza intelectual. La memoria de Nicolás Stepanovitch se ha deteriorado, sus ideas son dispersas, olvida los nombres y de todo ello resulta una dificultad para la escritura. Con todo, hay un rasgo, en el quicio de ese cuerpo decrépito y de su ánimo, en la articulación de lo físico y lo moral, que define más que cualquier otra cosa su estado. El insomnio pauta y da forma a sus días, los fragiliza y amenaza: «No dormir por la noche, es tener

[4] Sobre esta cuestión me he pronunciado en Sánchez Durá, N.: "Sobre que uno se muere" en Callejo, M. J., García Norro, J.J. y Rodríguez, R. (edits.): De la libertad del mundo. Homenaje a Juan Manuel Navarro Cordón. Madrid: Escolar y Mayo editores, 2014 y en Sánchez Durá, N.: "Léon Tolstói. Divina Anarquía" en Claves de la Razón Práctica 216, 2011.

[5] Wittgenstein, L.: Cuadernos de Notas (1914-1916). Madrid: Síntesis, 2009, p. 209 [anotación del 8/7/1916]. Por cierto, éste es el Wittgenstein que leía y releía en ese periodo El Evangelio Abreviado de Tolstói.

THÉMATA. Revista de Filosofía, №52 julio-diciembre (2015) pp.: 111-127 doi: 10.12795/themata.2015.i52.06 
en todo momento la consciencia de que no se es normal». ${ }^{6}$ Este desdoblamiento entre la percepción ajena de la que es objeto y la propia percepción de sí, entre su identidad social y su identidad personal, le permite transitar reflexivamente de un polo al otro. Una meditación que se acera a medida que se agudiza el desajuste entre ambas identidades. Chéjov muestra desde el inicio que esa va a ser la lógica de su relato. Una historia aburrida comienza dando la palabra a su personaje el cual se refiere a sí mismo en tercera persona - Existe en Rusia un profesor conocido por numerosos trabajos, de nombre Nicolás Stepanovitch, etc...»- y lo que sigue es una descripción objetivante del tal profesor compuesta por los rasgos públicamente más sobresalientes. Pero esa enunciación se rompe en el tercer párrafo donde la persona descrita pasa a convertirse en quien la describía: «El portador de ese nombre -dicho de otra forma, yo- ${ }^{7}$ » es un hombre de 62 años, etc.

A diferencia de Iván Ilich, con quien comparte reconocimiento social y estatus, Nicolás Stepanovitch no se ve sacudido por una enfermedad inesperada que resultará mortal. En este caso, no hay ningún brusco accidente que, dando un giro inesperado a su vida, le induzca a reflexionar sobre su pasado para concluir en la carencia de sentido de una vida considerada errada. En el caso de Nicolás Stepanovitch lo que hay es la inexorable vejez, aspecto subrayado por el subtítulo que Chéjov dio a esta novela, «Fragmento de las memorias de un hombre viejo». Cierto, Stepanovitch parece enfermo, pero en su caso no es una enfermedad terminal como la que padece Iván Ilich. Este último muere en su relato, que culmina de ese modo, mientras que en una Historia aburrida no sabemos qué pasará, si su personaje morirá pronto o tarde, si realmente está muy enfermo o si es así como se le percibe dada su decrepitud física y algunos síntomas inquietantes. Es decir, lo que le amenaza con intensidad creciente es lo que amenaza necesariamente a todos los que no mueren prematuramente. Pues la falta de sentido no se enseñorea ahora, como en el caso de Tolstói, en una determinada clase, en un determinado estamento, o en todos aquellos que viven de espaldas a los hombres recluidos en su bonanza material o en la ebriedad egoísta de la riqueza. En Una historia aburrida él, su hija Liza y su apadrinada Katia, personajes de muy distinta biografía, expresan esa carencia, si bien de distinta forma. Lo mismo ocurre con las apariciones esporádicas de otros personajes, como Piotr Ignatievich, su asistente sin talento, circunscrito a su especialidad, dedicado en cuerpo y alma a la rutina del laboratorio: «Hará toda su vida varios cientos de preparaciones extraordinariamente adecuadas,

[6] Tchekhov, A. Une banale histoire. Fragment des mémoires d'un homme vieux. Nouvelles. Traduit du russe par Denis Roche. Paris: Librairie Plon, 1923. La Biblothèque électronique du Québec. Collection Clasiques du 20 siècle. Volume 170: version 1.0, p. 11. Sigo esta edición por la que pagino, pero la cotejo con Chéjov, A. P.: Cinco novelas cortas. Traducción de Gallego Ballestero. Barcelona: Alba Editorial, 2008.

[7] Ibidem, p. 8.

THÉMATA. Revista de Filosofía, N52 julio-diciembre (2015) pp.: 111-127 doi: 10.12795/themata.2015.i52.06 
escribirá muchos tratados, convenientes y secos, hará decenas de traducciones concienzudas, pero no inventará pólvora alguna. Porque para inventar la pólvora, hace falta, fantasía, invención y adivinación y no hay nada parecido en Piotr Ignatievich; brevemente, no es un patrón de la ciencia, es un obrero». ${ }^{8}$

Este rasgo descriptivo de la poquedad del asistente nos lleva a un punto especialmente significativo del relato, prima facie paradójico, sobre el que volveré. A diferencia de Iván Ilich -o del propio Tolstói en Confesión, texto tan sólo cuatro años anterior y difícil de obviar cuando se lee ese relato- el desánimo de Nicolás Stepanovitch, su desfondamiento moral, no conlleva ni una impugnación ni una minusvaloración de la ciencia. Al contrario, para él merece su mayor aprecio. Confiesa que sólo la ciencia le interesa, y aún concediendo que esa fe puede ser "ingenua y mal fundada» admite que no puede "vencerla». Es más, con la perspectiva de la muerte futura, que atisba a través de los múltiples síntomas de su desfallecimiento, parece que debiera preocuparse, dice, de las tinieblas del más allá y, sin embargo, como a lo largo de toda su vida, "cuando rinda el último suspiro, continuaré creyendo que la ciencia es lo que hay de esencial, de lo más bello y más necesario en la vida del hombre, que siempre ha sido la manifestación más alta del amor, y que, solo por ella, el hombre vencerá la naturaleza y a sí mismo». ${ }^{9}$ Esto es así porque Stepanovich no solo avista la ciencia desde sus logros y utilidades, sino porque -como en el caso del arte- es vista también desde el ángulo de las virtudes epistémicas de alcance moral que su práctica exige. Es decir, ciencia y arte suponen independencia, sentimiento de libertad e iniciativa personal. Por la misma razón, incluso en ese tiempo de malestar y desfondamiento cuya armadura es la «indiferencia", dice leer solo libros franceses -y no de autores rusos- dadas las virtudes que la escritura de aquéllos supone: si es cierto que no todos los autores franceses poseen «ingenio», sin embargo son "generosos», tienen "talento» y se encuentra en ellos, como en el ejercicio de la ciencia, «el principal elemento de la creación: el sentimiento de libertad personal». ${ }^{10}$

Por otra parte, a diferencia del Iván Ilich de Tolstói, en el caso de Nicolás Stepanovitch tampoco hay una impugnación radical de la vida pasada, una negación de los valores que la presidieron. Lo acabamos de ver en el caso de la ciencia, pero lo mismo ocurre con su vida privada. Recuerda el pasado vivido como algo bello: sus ensoñaciones de estudiante, la infancia de su hija, sus juegos amorosos, su matrimonio apasionado, la alegría que convertía las comidas en una fiesta.....

«En una palabra, si miro hacia atrás, toda mi vida me parece bella, una composición feliz. Solo me queda no estropear el final. Para ello, es preciso morir como un hombre, ir al

[8] Ibídem, p. 26.

[9] Ibídem, p. 32.

[10] Ibídem, p. 96.

THÉMATA. Revista de Filosofía, №52 julio-diciembre (2015) pp.: 111-127 doi: 10.12795/themata.2015.152.06 
encuentro de la muerte valientemente y el alma tranquila como conviene a un maestro, a un sabio, a un miembro del reino de Cristo. Pero estropearé el final». ${ }^{11}$

Ese pesimismo respecto de su aspiración de estar vivo hasta morir, de no morir en vida, ${ }^{12}$ se cifra en múltiples alteraciones de su humor, algunas fáciles de enunciar, pero otras en absoluto porque apelan a algo más profundo. En cuanto a las primeras, le irritan o descree de las maneras corteses que siempre han regido entre él y sus colegas. Si se trata de su mujer e hija, las considera ajenas, desconocidas y dada esa sensación de extrañeza toda ritualidad familiar, antaño gozosa, se torna vacía. Ese sentimiento de extrañeza -que se muestra a menudo en forma de irascibilidad- alcanza los rasgos más generales de su percepción de los otros. Se reconoce triste, aburrido, deprimente. Si antaño era una persona «indulgente», se «abstenía de juzgar», "perdonaba», se dedicaba a "aconsejar» y "convencer», ahora le ocurre algo que es propio, dice, de «esclavos», pues sus emociones y sentimientos escapan a su dominio: «odio, desprecio, me indigno, me rebelo, y temo. Me he convertido en alguien excesivamente severo, exigente, irascible, mal complaciente y desconfiado». ${ }^{13}$ Es más, a medida que la angustia avanza, el malestar se transforma en un sentimiento de implosión, de pánico sin rostro, mudo si no es a través de los trastornos corporales, es decir, inefable si no es en forma de síntoma: «Mi pavor es irracional, animal; no comprendo por qué tengo miedo ¿es porque quiero vivir todavía o porque espero un nuevo sufrimiento insospechado?» ${ }^{14}$

Llegado a este punto Stepanovitch se pregunta si ha cambiado de convicciones, si es que el mundo ha empeorado y él ha mejorado, si es que antes no veía lo que ahora ve. A esas tres preguntas Iván Ilich, el personaje de Tolstói, responde afirmativamente en el estado avanzado de su enfermedad terminal, cuando revisa su vida pasada y acaba negándola in toto. Pero ese no es el caso de Stepanovitch, su malestar moral no anuncia una liberación, una transvaloración de los valores que han regido su vida. Ante su decrepitud física e intelectual, ante el fantasma de la muerte venidera no piensa que haya un derrotero general, un camino de resurrección en vida. Frente a la pregunta «¿Qué hacer?» de su querida prohijada Katia, que joven, libre y anti-convencional padece un progresivo malestar moral una vez desencantada del mundo del teatro en el que se había involucrado apasionadamente, Stepanovich descarta la respuesta que La muerte de Iván Ilich anuncia y el Tolstói posterior desarrollará; pregunta y respuesta prefiguradas ambas en su Confesión. ${ }^{15}$ Pues afirma

\section{[11] Ibídem, p. 77.}

[12] Cf. Ricoeur, P.: Vivo hasta la muerte. México: FCE, 2008; sobre este asunto me he expresado en "Sobre que uno se muere", op.cit.

[13] Tchekhov, A.: op. cit. p.73.

[14] Ibidem, p. 116.

[15] Tolstoi, L.: Confesión. Barcelona: Acantilado, 2008.

THÉMATA. Revista de Filosofía, Nº52 julio-diciembre (2015) pp.: 111-127 doi: 10.12795/themata.2015.i52.06 
Stepanovich que sería fácil decirle a Katia, y también decirse a sí mismo, "trabaja, o distribuye tu fortuna entre los pobres, o conócete a ti misma. Y porque todo eso es muy fácil de decir, no sé que responderle». ${ }^{16}$ Así, del mismo modo que los médicos individualizan cada caso, dice estar convencido de que tampoco las reglas generales sirven para «las enfermedades morales».

Ahora bien, a pesar de sus humores cambiantes y de su pánico ocasional, el relato repite una y otra vez que la característica moral más general que Stepanovitch se atribuye es la «indiferencia», una indiferencia que él identifica con una enfermedad anímica, con una muerte anticipada: «Se dice que los filósofos y los verdaderos sabios son indiferentes; es falso. La indiferencia es una parálisis del alma, una muerte anticipada». ${ }^{17}$ De manera que en un empeño de superarla racionalmente, Stepanovitch aplica al conocimiento de sí -precepto filosófico por antonomasia- el método de no examinar los actos sino los deseos: «Cuando antaño tenía ganas de comprender a alguien o a mí mismo, examinaba no sus actos, en lo cual todo es convencional, sino los deseos de ese alguien, o los míos. Dime lo que quieres, y te diré lo que eres...». ${ }^{18} \mathrm{~A}$ ello se dedica sin excesiva convicción: erráticamente encuentra esto y aquello (que próximos y extraños, amen en nosotros no nuestros nombres sino a seres ordinarios, despertarse dentro de cien años y ver qué fue de la ciencia y su devenir, vivir diez años más...). La enumeración parece incluir aspectos fundamentales si no fuera por lo errático de su encuentro. Así, busca qué más pueda desear pero no logra imaginarse nada más. En esa meditación encuentra la razón de su indiferencia, de su desafección incluso por aquello que parece desear. A saber, la desarticulación de los aspectos de su vida, la imposibilidad de integrarlos en un todo unitario cuyo sentido general dote de lugar, orden, jerarquía, interés, en definitiva de sentido a las partes constitutivas: el amor, las relaciones familiares, las relaciones sociales, la academia, la investigación, el desarrollo científico, las artes...:

«En mi pasión por la ciencia, en mi deseo de vivir....en mi esfuerzo por conocerme a mí mismo, en todos los pensamientos, emociones y conceptos que me he formado, falta un vínculo común capaz de religar todo ello en un todo...Cada sentimiento y cada pensamiento viven en mí por separado y en todos mis juicios sobre la ciencia, el teatro, la literatura o mis alumnos, en todos los cuadros que dibuja mi imaginación, ni siquiera el más experto analista lograría encontrar lo que se llama una idea común y general, que es el dios de un hombre vivo. Y, si eso falta, entonces es que no hay nada». ${ }^{19}$

Recordemos ahora el dictum de Wittgenstein: «Creer en un dios significa ver que la vida tiene un sentido».

[16] Tchekhov, A.: op. cit. p. 109.

[17] Ibidem, p. 127.

[18] Ibidem, p. 128.

[19] Ibidem, p. 129.

THÉMATA. Revista de Filosofía, №52 julio-diciembre (2015) pp.: 111-127 doi: 10.12795/themata.2015.i52.06 
La crisis de sentido que Chéjov expresa a través de su nouvelle difiere en aspectos decisivos de la de Tolstói tal como aparece en La muerte de Iván Ilich y en su obra posterior. En principio, la actitud de sus respectivos personajes ante la enfermedad es muy distinta. Si es cierto que cualquier persona seriamente enferma fragua un estilo propio del enfermar ${ }^{20}$-que se refleja en el relato que hace de su enfermedad y en su modo de estar enfermo-, Iván Ilich y Stepanovitch desarrollan dos estilos harto diferentes. Iván Ilich vive aterrorizado por el desarrollo de su enfermedad, Stepanovich no. Iván Ilich lo intenta todo para zafarse de ella, Stepanovitch ni siquiera acepta los consejos y la ayuda económica para dejarse diagnosticar y tratar. ${ }^{21}$ Ante la inminencia de la muerte, Iván Ilich niega su vida tal como era antes de enfermar, negación que no se produce definitivamente hasta que acepta que su mal lo ha de matar. $\mathrm{Su}$ vivencia de la muerte en ante-futuro (Ricoeur) -es decir: el verse desde la perspectiva del muerto que será a los ojos de los otros cuando él ya no esté en este mundo- es la ocasión para optar por otros valores (fundamentalmente la fraternidad y la no violencia entre los hombres); para transformar su identidad moral y propugnar otra forma de vida que concibe como auténtica (que Tolstói consideraba divina). La situación de Stepanovitch, aunque en apariencia es semejante, difiere notablemente. Cierto es que su vejez y la enfermedad -que aquí y allá en el texto se nos deja adivinar como severa pero no terminal- le hace volver sobre su fama adoptando un punto de vista distanciado, entre burlesco, irónico y escéptico: «no amo la popularidad de mi nombre. Me parece que, de alguna manera, me ha engañado». ${ }^{22}$ Pero su popularidad le ha engañado sobre el grado de relevancia de ciertos aspectos a los que les ha concedido demasiada importancia. Ahora bien, reconsiderar la dimensión o la relevancia de algunos aspectos de su vida pasada no es negarla radicalmente, como era el caso de Iván Ilich. Stepanovitch admite -aunque ya vimos que consideraba su vida pasada como «una composición feliz» no desprovista de belleza-, admite, digo, «que todo lo que antes llamaba mi concepción del mundo, y en lo que veía el sentido y la alegría de mi existencia... ha volado en pedazos». ${ }^{23}$ Pero a diferencia de Iván Ilich no hay algo otro imaginable que reconstruya la unidad de sentido perdida. Cierto, él ha llegado a ese punto de desesperanza y de indiferencia o bien a través de la experiencia de la decrepitud de la vejez, o bien a través de

[20] Broyard, A.: Ebrio de enfermedad. Segovia: Ediciones la Uña Rota, 2013, p. 49.

[21] Aunque hablamos de su personaje y no de él, Chéjov tuvo su primer vomito de sangre muy pronto, en 1884, a los 24 años. Lo ocultó a todos. En 1897 tuvo el más grave hasta ese momento y fue ingresado en el hospital. Tolstói estuvo entre los amigos que lo visitaron.

[22] Tchekhov, A.: op. cit., p. 126.

[23] Ibídem, p. 129.

THÉMATA. Revista de Filosofía, Nº52 julio-diciembre (2015) pp.: 111-127 doi: 10.12795/themata.2015.i52.06 
la enfermedad (aspectos que en él se confunden siquiera sea simbólicamente). Pero también afirma que no es necesaria una experiencia límite, bastaría con un constipado:

«Cuando un hombre carece de algo que sea más poderoso y elevado que las influencias externas basta un resfriado para que pierda el equilibrio y empiece a ver una lechuza en cada ave y a oír el aullido de un perro en cada rumor. En ese momento, todo su optimismo o pesimismo, así como sus pensamientos grandes y pequeños, adquieren el significado de un mero síntoma» ${ }^{24}$.

Por decirlo con terminología wittgensteiniana, lo verdaderamente relevante es el momento en que se ve la vida bajo otro aspecto, sintiéndose desvinculado, retraído respecto de lo que en ella acontece. Y el relampaguear de ese aspecto bien puede darse bajo circunstancias distintas, si bien una vez dado, la vida, así avistada, ya no puede recuperarse con el aspecto de antaño.

Que no es precisa la inminencia de la muerte, o su fantasma, para que desde la indiferencia el mundo se desrealice, se muestra en el caso de Katia, la huérfana prohijada por Stepanovitch. Katia no es vieja, es joven; no está consumida por la edad, es bella; no es una académica, sino una persona que ha estado del todo implicada en el mundo del teatro. No ha tenido ni un matrimonio ni una familia pequeño burguesa, sino una vida libre, carente de las cortapisas que las convenciones sociales imponen. Tampoco tiene estrecheces económicas como Stepanovich, pues es adinerada por herencia. Y sin embargo Katia es presa del mismo desfondamiento moral que Stepanovitch. Ante su confesión de no poder seguir viviendo en ese estado, ante su reiterado preguntar a Stepanovitch qué hacer -«usted que es culto, inteligente, que ha vivido tanto, que ha sido enseñante»-, éste le responde "no puedo decirte nada...en conciencia, no lo sé». Stepanovitch concluye: «No he reparado en la ausencia de lo que los filósofos llaman una idea general más que poco antes de mi muerte, en el declive de mis días y el alma de esta pobre pequeña no ha conocido ni conocerá paz en toda su vida». ${ }^{25}$

Sin embargo, a pesar de que la situación de Stepanovich y de Katia tiene rasgos comunes -la indiferencia, la desesperanza, la desrealización del mundo-, hay algo que los distingue. Para decirlo brevemente: Katia se encuentra en un estado luctuoso o de duelo, Stepanovich es un melancólico. La acedia los emparenta (si quiere decirse en un lenguaje teológico que no es el de Chéjov), pero también los distingue. En la descripción que de Katia se hace, el punto de partida es que «El teatro era, para ella, la fuerza que reúne en una sola todas las artes, y los actores, misioneros». ${ }^{26}$ Cuando se une a una troupe y parte para un largo periplo, lleva consigo «una masa de radiantes esperanzas

[24] Ibidem, p. 130.

[25] Ibídem, p. 132, 133 y 134 respectivamente.

[26] Ibídem, p. 48.

THÉMATA. Revista de Filosofía, №52 julio-diciembre (2015) pp.: 111-127 doi: 10.12795/themata.2015.i52.06 
y de concepciones aristocráticas del teatro». ${ }^{27}$ Gasta su dinero en ello, viaja, se entusiasma, se enamora. De regreso a casa tras cuatro años Katia no abomina del arte, pero sí de los que protagonizan el mundo del teatro:

«es un rebaño de salvajes que se han subido a la escena porque no los habrían admitido en ninguna otra parte y que no se llaman artistas si no es por imprudencia. No hay ni un talento, muchos fracasados, borrachos, intrigantes y chismosos. No puedo decirle cómo me aflige que el arte, que amo tanto, haya caído en manos de gente que odio». ${ }^{28}$

Su bien amado resulta ser uno de esos «salvajes», Stepanovich cree que ha intentado en una ocasión suicidarse por envenenamiento y sabe por una carta que ha enterrado a su hijito. La acedia ${ }^{29}$ de Katia se debe pues al duelo por una pérdida definida.

Pero el caso de Nicolás Stepanovich es distinto. No se trata del duelo por una pérdida definida, sino de un estado melancólico. En su escrito Duelo y melancolía (1917) Freud emparenta, pero distingue, el duelo y la melancolía. En el duelo se da la pérdida real de un objeto de afecto, en la melancolía no sólo no está definido lo que se ha perdido sino que ni siquiera está claro que se pueda hablar de una pérdida real. Tratando de dar cuenta de la paradoja de una pérdida a la que no corresponde un objeto perdido, Freud habla después de "una pérdida desconocida» o "de una pérdida objetual que escapa a la conciencia». ${ }^{30}$ Cierto, cuando intenta dar cuenta de su acedia, de su indiferencia, Stepanovich afirma la falta de "una idea común y general, que es el dios de un hombre vivo», si se carece de ello [dice], no hay "nada». Es decir, habla como si se tratara de la pérdida de algo perteneciente al orden de lo teórico, de lo especulativo, de lo filosófico si se prefiere. Pero también es cierto, como ya he citado, que en otro momento se refiere a ello diciendo que «cuando un hombre carece de algo que sea más poderoso y elevado que las influencias externas basta un resfriado para que pierda el equilibrio y empiece a ver una lechuza en cada ave y a oír el aullido de un perro en cada rumor». Asímismo, en otro pasaje ya citado, dice no haber «reparado en la ausencia de lo que los filósofos llaman una idea general más que poco antes de mi muerte, en el declive de mis días etc...»

[27] Ibídem, p.49.

[28] Ibidem, p.52.

[29] En numerosos pasajes a Katia se la asocia a la indiferencia y a la pereza. Después de su desencantado regreso, su casa se describe así: "Si uno intentaba representar su interior, el elemento preponderante sería la pereza. Mullidas chaises longues para cuerpos perezosos, blandos taburetes para piernas perezosas, tapices de colores desvaídos o de colores mates para los ojos perezosos; en las paredes, para el alma perezosa, abundantes abanicos...todo esto atesta la pereza del alma..Katia permanece tumbada días enteros en su chaise longue y lee sobre todo novelas y nouvelles", Ibídem, p. 54.

[30] Sigo a Agamben, G.: Estancias, La palabra y el fantasma en la cultura occidental. Valencia: Pretextos, 1995, p. 52 .

THÉMATA. Revista de Filosofía, ${ }^{\circ} 52$ julio-diciembre (2015) pp.: 111-127 doi: 10.12795/themata.2015.i52.06 
¿De qué carácter es pues ese «algo» que no es tanto que Stepanovich haya perdido, sino que su ausencia ha escapado a su conciencia y que, con ocasión de la vejez, vive como una pérdida? Dicho con palabras de Agamben: «la melancolía no sería tanto la reacción regresiva ante la pérdida del objeto de amor, sino la capacidad fantasmática de hacer aparecer como perdido un objeto inapropiable». ${ }^{31}$ Es decir: Stepanovich no perdió, sino que nunca poseyó «ese dios del hombre vivo», es decir, nunca dispuso, o solo dispuso fantasmáticamente, de «ese vínculo común capaz de religar todo ello en un todo» $\mathrm{y}$, por tanto, siempre estuvo ante la nada. El Iván Ilich de Tolstói quiere matar a la muerte y, "resucitado" a una nueva concepción de la vida que considera merece ser vivida, su última palabra es «este es el fin de la muerte...la muerte ya no existe». Iván Ilich sutura la herida del sinsentido a través del modelo de su criado Guerasim, que reúne todas las virtudes morales que Tolstói atribuía a los mujik. La nueva vida a la que los hombres deben renacer debía estar presidida por los valores que de siempre los mujiks encarnaban. Stepanovitch, sin embargo, no se refugia en ninguna humanidad abstracta. Su propósito es mínimo: al principio de su relato de memoria había dicho que quería morir como un hombre, ir al encuentro de la muerte valientemente con el alma tranquila, su sola preocupación era no «estropear el final». Al término de sus memorias, solo, lejos de casa en la ciudad extraña de Jarkov, afirma que

\footnotetext{
«como sería inútil, y está más allá de mis fuerzas luchar contra mi disposición de ánimo actual, he decidido que los últimos días de mi vida sean irreprochables, al menos desde un punto de vista formal...por lo demás, me he convertido en alguien tan indiferente a todo que me da lo mismo ir a Jarkov, a París o a Berdíchev». ${ }^{32}$
}

Y en ese punto se instala el silencio y no caben ni la meditación, ni las preguntas generales, tampoco las respuestas particulares, solo el silencio. El silencio ante el otro (afirmando frente a Katia que verdaderamente no sabe qué responder a su pregunta de qué hacer), el silencio ante sí: «Estoy vencido. Si esto es así, no hay por qué continuar pensando, ya no hay que hablar de ello... me quedaré así y esperaré en silencio lo que será». ${ }^{33}$

Y sin embargo hay una ambivalencia en Stepanovich. Hemos visto que ni en sus momentos más lúgubres abandona su fe en la ciencia, le exasperan los decadentistas que la impugnan y lee autores franceses porque tienen independencia de criterio, libertad personal. Es más, cuando al final del relato Katia lo visita en Jarkov y lo apremia una vez más con su reiterada pregunta de qué hacer, cuando Stepanovich, como hemos visto, se instala en el silencio y

[31] Ibidem, p. 53.

[32] Tchekhov, A.: op. cit., p. 123.

[33] Ibidem, p. 130.

THÉMATA. Revista de Filosofía, №52 julio-diciembre (2015) pp.: 111-127

doi: 10.12795/themata.2015.i52.06 
le contesta «no puedo decirte nada...en conciencia, no lo sé», sin embargo, con todo, al verla partir, se dice a sí mismo «iAdiós mi tesoro!». Esas son las últimas palabras del relato de Chéjov.

¿Cómo puede el supremo indiferente tener fe en la ciencia o considerar a la joven y bella Katia, expresión de la vida aunque también abatida, "un tesoro»? Freud calificó la melancolía de ambivalente, como uno de esos compromisos que solo son posibles en los procesos inconscientes. Escuchemos de nuevo a Agamben:

\begin{abstract}
«en la melancolía el objeto no es ni apropiado ni perdido, sino una cosa y otra al mismo tiempo. Y así como el fetiche es a la vez signo de algo y de su ausencia, y debe a esta contradicción su propio estatuto fantasmático, así el objeto de la melancolía es al mismo tiempo real e irreal, incorporado y perdido, afirmado y negadom. ${ }^{34}$
\end{abstract}

Pues bien, esa es la razón de que Stepanovich dijera que cuando un hombre carece de algo que sea más poderoso y elevado que las influencias externas todo su optimismo o pesimismo, así como sus pensamientos grandes y pequeños, adquieren el significado de un mero síntoma. Podemos decir nosotros: un síntoma de su melancolía. Pues cualquier síntoma siempre remite a una causa, y la vejez y la enfermedad, como advocaciones de la muerte, le han hecho ver que pesimismo y optimismo no eran más que efectos rapsódicos de diferentes causas externas que no pueden sustituir «ese vínculo común capaz de religar todo ello en un todo», careciendo así aquellas alegrías de antaño del sentido que él equivocadamente les atribuía. ${ }^{35} \mathrm{Y}$ esa creo es la actitud que caracteriza a Stepanovich ante el sentido de la vida.

Ahora bien, ¿qué puede querer decir «vivir irreprochablemente hasta el final al menos desde un punto de vista formal» para alguien que se decide por el silencio dado el sinsentido de la vida? Si miramos al propio Chéjov, a cómo se comportó respecto de la tisis que lo habría de matar, podemos obtener un primer atisbo. Como su personaje, Chéjov vivió vadeando su enfermedad, restándole importancia sin hacerla presente a sus próximos, encargándose de su madre y hermanos hasta el último momento. Ya muy tardíamente se enamoró de Olga Knipper, una actriz de talento, y se casó con ella. Chéjov la alentó siempre a que siguiera recorriendo con éxito los escenarios de Rusia y de Europa. Por su parte, no dejó de hacer largos viajes, de escribir, de ser quien había sido hasta el mismo final..$^{36}$ Raymon Carver, en Tres rosas amarillas, describe sus últimos momentos haciendo acopio de sus biografías. En el mes de junio de 1904 Chéjov

[34] Agamben, G.: op. cit., p.54, mío el énfasis.

[35] Debo esta última formulación a la discusión con mi colega Julián Marrades Millet. Por lo demás, este texto está empapado de las discusiones en el seminario Literatura y Filosofía cuya alma radica en otro querido colega, Joan Bautista Llinares Chover.

[36] Véase Ginzburg, N.: Antón Chéjov. Barcelona: Acantilado, 2006 y Lafitte, S.: Chéjov según Chéjov. Barcelona: Editorial Laia, 1973.

THÉMATA. Revista de Filosofía, №52 julio-diciembre (2015) pp.: 111-127 doi: 10.12795/themata.2015.i52.06 
llegó al balneario alemán de Badenweiler para morir. La noche del 2 de julio de 1904 tuvo una crisis aguda. Su mujer llamó al doctor Schwohrer que vio que había llegado el final. Sorprendentemente, llamó a un camarero y pidió una botella de champán y tres copas. Descorchó la botella, nos cuenta Carver,

«cuidando de atenuar al máximo la explosión festiva...Luego llevó las tres copas hasta la cabecera del moribundo. Olga... colocó otra almohada bajo su nuca. Los tres intercambiaron miradas: Chéjov, Olga, el doctor Schwohrer. No hicieron chocar las copas. No hubo brindis. ¿En honor de qué diablos iban a brindar? ¿De la muerte? Chéjov hizo acopio de las fuerzas que le quedaban y dijo: «Hacía tanto tiempo que no bebía champaña...». Se llevó la copa a los labios y bebió. Uno o dos minutos después Olga le retiró la copa vacía de la mano... Chéjov se dio la vuelta en la cama y se quedó tendido de lado. Cerró los ojos y suspiró. Un minuto después dejó de respirar». ${ }^{37}$

No puede negarse que su final fue irreprochable al menos desde «un punto de vista formal». De cierta manera, aunque con muy distinta forma, puede recordar el final de Wittgenstein. Momentos antes de perder la consciencia rogó a la sra. Bevan -esposa del médico al que había pedido aposento en su casa para morir- que dijera a sus amigos que "había tenido una vida maravillosa». Ambos, por decirlo con Wittgenstein, vivieron su muerte como un «instante bienaventurado». ${ }^{38}$

Pero insistamos, ¿Qué puede querer decir «vivir irreprochablemente hasta el final" una vez se ha expresado melancólicamente la ausencia de sentido de la vida? O por decirlo de otra manera: ¿Qué moral es en absoluto posible bajo tal premisa?

De la reconstrucción religiosa del sentido en Tolstói se deduce una moral y una política claras. El sentido de la vida, por decirlo con una de las últimas formulaciones de Tolstói, radica en "la más elevada y, en realidad, la única ley de la vida...el esfuerzo de las almas de los seres humanos hacia la unidad y el comportamiento dócil entre sí que resulta de ello». ${ }^{39}$ Esa ley es lo sagrado (que en momentos anteriores Tolstói tantas veces llama «la voluntad de Dios»), y en lo que tiene de fundamento de una norma de conducta se traduce en empeñarse en un mundo donde prevalezcan los vínculos fraternos, un luchar con los otros por la afirmación de la vida, que en cuanto alegre, derrota el miedo y la angustia frente a la muerte. Una lucha y un empeño que conlleva necesariamente una denodada implicación social y política pero donde,

[37] Carver, R.[en línea]: Tres rosas amarillas, http://www.lamaquinadeltiempo.com/prosas/ carver01.htm

[38] «El instante terrible en una muerte desventurada tiene que ser pensar: «Oh, si hubiera... Ahora ya es demasiado tarde». ¡Oh si hubiera vivido correctamente! Y el instante bienaventurado tiene que ser: «Ya está todo cumplido!...», Wittgenstein, L.: Movimientos del pensar. Diarios 19301932/1936-1937. Valencia: Pretextos, 2000, p. 110.

[39] "Carta a Gandhi del 7 de septiembre de 1910 en Tolstói, L.: El Reino de Dios está en vosotros. Barcelona: Kairós, 2009, Apéndice (sin paginación).

THÉMATA. Revista de Filosofía, №52 julio-diciembre (2015) pp.: 111-127

doi: 10.12795/themata.2015.152.06 
por cierto, el bien de la Humanidad no puede abolir o posponer el cuidado benévolo de las personas de carne y hueso. Y tal lucha, tal vínculo amistoso y comprensivo, la verdadera vida, tiene su centro en el presente. ${ }^{40}$ Sabida es la implicación directamente política de Tolstói, sus llamadas a no pagar impuestos que fueran a los ejércitos, a resistirse al reclutamiento, su lucha contra el sistema penal zarista, por la abolición de la pena de muerte, en defensa de la educación para todos, la rebaja de las horas de trabajo, su crítica del imperialismo inglés, del militarismo, etc. Sabida es la decisiva influencia que tuvieron en Gandhi los escritos de Tolstói, al cual conoció precisamente a través de sus proclamas llamando a la resistencia no violenta frente al colonialismo de la corona británica en la India.

Pues bien ¿qué moral puede ser acorde con la melancolía de Chéjov tal como la he descrito aquí? Mi pregunta, es obvio, va más allá del caso del personaje de Stepanovich y creo que para contestarla no es disparatado sino oportuno referirme a la obra central de uno de los grandes escritores judeo-rusos del siglo pasado, Vida y Destino de Vasili Grossman. Esa novela, escrita con la voluntad de ser La Guerra y Paz de la guerra contra el nazi/fascismo, está recorrida toda ella por una confrontación de Tolstói y Chéjov. Una confrontación explícita en varias ocasiones, que toma la forma de una discusión de los personajes sobre la significación de ambos autores; otras muchas implícita, en forma de alusión intertextual en momentos clave de la novela (por ejemplo, cuando la madre del físico Shtrum, alter ego de Grossman, en su carta de despedida desde el gueto, adivinado su exterminio, le dice que ha llevado con ella el libro de Chéjov donde aparecen los relatos Una historia aburrida y El Obispo). ${ }^{41} \mathrm{Ya}$ Todorov subrayó en su libro Memoria del mal, tentación del Bien ${ }^{42}$ el punto de vista moral fundamentalmente chejoviano de Grossman (si bien es obvio que, desde el punto de vista formal, Vida y Destino sigue el modelo literario de Guerra y Paz). Téngase en cuenta que Grossman, cuando escribe su obra en los primeros años 60 del siglo pasado, no solo es un agnóstico, sino un acerado crítico de aquello que él mismo fue, a saber, un bolchevique. Un bolchevique que había dejado de serlo porque en su feroz crítica al estalinismo se había retrotraído a los tiempos de la revolución de 1917 y a lo que ésta tenía de germen del terror posterior de los años 30. Es decir, Grossman ni participa de un sentido

[40] «La verdadera vida, la que realiza la voluntad del padre, no es la que pasó, ni la que será, sino la vida de ahora. Y por eso no se debe flaquear nunca ante la veracidad de la vida. Los hombres no tienen que preocuparse por la vida pasada ni la futura, sino por la que viven, y en ella cumplir la voluntad del padre de todos.....Y por eso el hombre debe trasladar toda su fuerza al momento presente; sólo en él se puede cumplir la voluntad del padre. La voluntad del padre es la vida y el bien de todos los hombres y, por eso, cumplir la voluntad del padre es el bien para todos los hombres. Sólo viven los que hacen el bien» Tolstoi, L.: El Evangelio Abreviado. Oviedo: KRK, 2006, p. 208-209. Mío el énfasis.

[41] Grossman, V.: Vida y Destino. Barcelona: Círculo de Lectores, 2007, cap. 18, Iª parte, p. 97.

[42] Todorov, T.: Memoria del mal, tentación del Bien. Barcelona: Península, 2002.

THÉMATA. Revista de Filosofía, Nº52 julio-diciembre (2015) pp.: 111-127 doi: 10.12795/themata.2015.i52.06 
trascendente de la vida, ni de la teleología histórica del bolchevismo soviético. Pues bien, voy a referirme principalmente a un capítulo de su novela que se desarrolla en un campo nazi donde están concentrados prisioneros de guerra del Ejército Rojo. ${ }^{43}$ Entre esos prisioneros hay uno (Ikónnikov) calificado por el narrador/Grossman como "extolstoiano» y tildado de «menchevique» por sus compañeros de cautiverio bolcheviques. Lo que piensa este "extoltoiano» la novela nos lo muestra en una situación significativa. Un miembro (Mostovskói) de la vieja guardia bolchevique de los tiempos previos a la Revolución de Octubre está recluido y separado en una celda de castigo. No lo quieren torturar, ni interrogar, está ahí porque un oficial de las SS (Liss), descrito como un bruto movido por el interés teórico de comprender hasta sus entrañas al enemigo, quiere hablar con él. Le quiere convencer de que el nazismo y el bolchevismo tienen la identidad de los contrarios, es decir, se pueden oponer irreconciliablemente porque comparten género político (según Grossman ambos son muestras del nacionalismo y del totalitarismo). ${ }^{44}$ Pues bien, en ese contexto, el oficial nazi le pasa al bolchevique, para que lo lea de regreso a su celda, un manuscrito que sí sería ajeno a la lógica que según el alemán les mueve a ambos: un manuscrito que resulta haber sido redactado por el prisionero "extolstoiano» al que se le había confiscado. Es ese manuscrito el que me interesa y no los análisis político-históricos de Grossman.

El manuscrito comienza señalando la dificultad de definir la idea de Bien. Cómo ésta ha sido especificada muy diversamente a lo largo de la historia y cómo en esas especificaciones «el concepto mismo de ese bien se convertía en un látigo, en un mal más grande que el propio mal». ${ }^{45}$ Ocurre que el bien, en sus encarnaciones históricas, ha solido perder su universalidad y, so capa engañosa e impostada de la misma, no ha sido más que pretexto de la lucha de una secta religiosa, de una clase, de una nación o de un estado para justificar su lucha contra lo que desde cualquiera de esas instancias se ha definido como mal. Cada vez que ha despuntado un mundo nuevo presidido por una idea de bien eterno, corre la sangre y el sufrimiento. Por tanto, el «extolstoiano» del campo de concentración en vez de perseguir una idea de bien, prefiere hablar no de bien sino de «bondad». Esa bondad «podríamos denominarla bondad sin sentido. La bondad de los hombres al margen del bien religioso y social», dice Grossman. ${ }^{46}$ Esa bondad sin sentido es «pequeña», «sin testigos», «sin ideología», "particular», «casual», "absurda», también es «muda», «silenciosa», "vive

[43] Véase Grossman, V.: op. cit., cap. $16 \mathrm{II}^{\mathrm{a}}$ parte, passim.

[44] Por ejemplo, el SS Liss le dice al bolchevique Mostovskói: «somos formas diferentes de una misma esencia: el Estado de Partido....Ustedes saben tan bien como nosotros que el nacionalismo es la fuerza más poderosa del siglo XX. ¡El nacionalismo es el alma de nuestra época! ¡El socialismo en un solo país es la expresión suprema del nacionalismo!», Ibídem, p. 509 y p. 510.

[45] Ibidem, p. 513.

[46] Ibidem, p. 517.

THÉMATA. Revista de Filosofía, №52 julio-diciembre (2015) pp.: 111-127 doi: 10.12795/themata.2015.152.06 
en el corazón humano", todos esos predicados le atribuye Grossman. ${ }^{47}$ Es decir: la moral minimalista que se desprende de los escritos del «extolstoiano» y chejoviano Grossman es muda y silenciosa porque aunque bebe de las experiencias históricas de los hombres (la generosidad heroica de los que lucharon en la batalla de Stalingrado, la resistencia frente al fascismo, los comportamientos altruistas en las persecuciones antisemitas, la resistencia a la deshumanización en los campos de concentración, etc.), digo que esa moral minimalista se califica de muda y silenciosa porque si bien bebe de las experiencias históricas, no necesita de una imponente teoría abstracta que la justifique, porque no tiene afán de totalidad, porque se basa en la ejemplaridad de comportamientos concretos de individuos concretos en situaciones concretas. De manera que es una moral donde cobra importancia fundamental el contexto, la situación particular en la que se dan las acciones bondadosas de ciertas gentes de sensibilidad moral humanista. Así interpreto que Grossman la califique de «particular» y «casual». En otro momento, cuando un bolchevique que será posteriormente depurado (Krímov), se hace cábalas de por qué bolcheviques de la vieja guardia, intachables en su entrega y generosidad, permitieron en silencio los crueles juicios y depuraciones de sus camaradas, uno tras otro, inexorablemente, el narrador baraja la hipótesis del «miedo al Estado». Pero de inmediato se corrige y le atribuye este pensamiento: “ ¡No, no! El miedo no es capaz de realizar por sí solo semejante tarea. El fin superior de la revolución libera de la moral en nombre de la moral, justifica en nombre del futuro...» ${ }^{48}$

La literatura, por lo menos la literatura que a mí me gusta, en eso estoy de acuerdo con Wittgenstein, muestra más que dice. Toda Vida y Destino está recorrida por ejemplos de esa «bondad sin sentido» ejemplar. Para empezar el del propio "extolstoiano» preso, ejecutado por resistirse a trabajar en la construcción del campo de exterminio; o el de la judía Sofía Osipova, que se niega a revelar su condición de médico en la selección previa a la cámara de gas para no salvar momentáneamente el pellejo a costa de contribuir con su saber al mantenimiento del mecanismo del campo; o el del coronel Darenski, oficial del Estado Mayor del Ejército Rojo en el frente de Stalingrado que tacha de miserable a un coronel que tras la victoria patea a un prisionero alemán que se arrastra extenuado en la fila de prisioneros; o aún el presidente del Instituto Científico, Chepizhin, que dimite porque no quiere contribuir al desarrollo de la fisión nuclear, pues sabe los fines armamentísticos inmediatos a los que está destinada. También es el caso de los dos soldados, uno alemán, el otro ruso que cuando caen en el mismo embudo en un bombardeo, tras mirarse cara a cara, no se agreden sino que mutuamente se permiten volver a sus líneas respectivas porque ambos se reconocen en su miedo y afán de vivir, etc. Sólo diré aquí,

[47] Ibidem, p. 512 y ss.

[48] Ibídem, cap. $39 \mathrm{II}^{\mathrm{a}}$ parte, p. 674.

THÉMATA. Revista de Filosofía, Nº52 julio-diciembre (2015) pp.: 111-127 doi: 10.12795/themata.2015.i52.06 
sin más consideración, que esa bondad absurda me trae al recuerdo el hombre rebelde de Albert Camus

La moral de Grossman se basa en el supuesto de que el mal, mejor, las maldades, los daños son más evidentes que el Bien y que la experiencia histórica nos muestra que los hombres han sido ejemplares en ocasiones por su resistencia ante el mal y el daño incluso en situaciones límite. Paradójicamente, el feroz crítico del estalinismo, incluso del bolchevismo tout court, aprendió esa lección en la larga marcha que le llevó como corresponsal de guerra junto al Ejército Rojo de Moscú a Berlín, pasando por la gesta de Stalingrado y el terror de Treblinka, del cual fue uno de los primeros en escribir. ${ }^{49}$ Sin duda esa moral no solo es acorde, sino que está inspirada en la imposibilidad de encontrar un sentido a la vida tal como se muestra en el melancólico personaje Nicolai Stepanovich de Chéjov. Sin duda, es una moral mínima, tampoco parece posible que se desprenda de aquí una política (aunque sí intervenciones políticas circunstanciadas, puntuales, sin afán de totalidad), pero muestra cómo se puede vivir honesta e irreprochablemente aunque se carezca de un Dios de los cielos o de la historia -y así poder tomar una última copa de champán llegado el momento, si es que el dolor no es tal que seamos absorbidos por nuestro cuerpo doliente y no quepa distancia alguna de él.

[49] Véase Grossman, V.: Años de guerra. Barcelona: Círculo de lectores, 2009. Cap. "El infierno de Treblinka" y Ehrenburg, I y Grossman, V.: El libro negro. Madrid: Galaxia Gutenberg, 2011. 
